\title{
FACTORS RELATED TO DIFFICULTY SLEEPING IN ADULTS AND OLDER PEOPLE REGISTERED WITH THE FAMILY HEALTH STRATEGY
}

\section{Fatores relacionados à dificuldade de dormir em adultos e idosos cadastrados na Estratégia Saúde da Família}

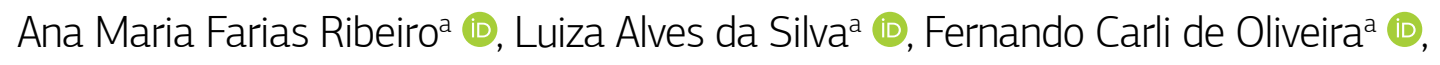 \\ Tatiana Carvalho Reis Martins ${ }^{\mathrm{b}}$ (1), Bruna Moretti Luchesi ${ }^{\mathrm{b}}$ (1)
}

OBJECTIVE: To identify the factors related to difficulty sleeping in adults and older people registered on the Family Health Strategy at Primary Care Health Centers. METHODS: This is a cross-sectional, quantitative study conducted in the town of Três Lagoas (MS, Brazil), with 300 people of both sexes, aged 45 years and over, registered on the town's Family Health Strategy. Data were collected using a structured questionnaire containing questions on sociodemographics, health, and social support networks. The dependent variable difficulty sleeping was assessed using the question: "Do you have difficulty sleeping?" Data were analyzed with binomial logistic regression. RESULTS: The prevalence of difficulty sleeping was 43\% (95\% confidence interval [95\%Cl] 37 - 49). According to the adjusted analyses, the following variables were associated with the outcome: female sex (Odds Ratio $=2.08 ; 95 \% \mathrm{Cl} 1.21-3.60$ ); number of medications per day (Odds Ratio $=1.18 ; 95 \% \mathrm{Cl} 1.05-1.33$ ); self-report of visual impairment (Odds Ratio $=3.56 ; 95 \% \mathrm{Cl}$ $1.54-8.25$ ); self-report of hearing loss (Odds Ratio = 2.28; 95\%Cl 1.18 - 4.41); and social isolation (Odds Ratio = 2.01; $95 \% \mathrm{Cl} 1.14$ - 3.54). CONCLUSIONS: Identification of the principal factors related to complaints of insomnia is of relevance to support planning of care and of public policies, targeting improved sleep quality in people going through the aging process and beyond.

KEYWORDS: aging; sleep; primary healthcare.

OBJETIVO: Identificar os fatores relacionados à dificuldade de dormir em adultos e idosos cadastrados em Unidades Básicas de Saúde com Estratégia Saúde da Família. METODOLOGIA: Trata-se de um estudo transversal e quantitativo, realizado em Três Lagoas (MS), com 300 indivíduos, de ambos os sexos, com idades a partir de 45 anos, cadastrados na Estratégia Saúde da Família do município. Para a coleta de dados foi utilizado um questionário estruturado contendo questões sociodemográficas, de saúde e de rede de apoio social. A variável dependente dificuldade de dormir foi avaliada pela questão: "O(a) senhor(a) tem dificuldade de dormir?”. Na análise dos dados, executou-se uma regressão logística binomial. RESULTADOS: A prevalência de dificuldade de dormir foi de 43\% (intervalo de confiança de 95\% [IC95\%] 37 - 49). De acordo com análises ajustadas, foram associados ao desfecho: sexo feminino (Odds Ratio = 2,08; IC95\% 1,21 - 3,60), número de medicamentos por dia (Odds Ratio = 1,18; IC95\% 1,05 - 1,33), autorrelato de déficit visual (Odds Ratio = 3,56; IC95\% 1,54 - 8,25), autorrelato de déficit auditivo (Odds Ratio = 2,28; IC95\% 1,18 - 4,41) e isolamento social (Odds Ratio = 2,01; IC95\% 1,14 - 3,54). CONCLUSÕES: A definição dos principais fatores relacionados às queixas de insônia é relevante para auxiliar o planejamento dos cuidados e de políticas públicas, com isso visando melhorar a qualidade do sono nos indivíduos em processo de envelhecimento e na velhice.

PALAVRAS-CHAVE: envelhecimento; sono; atenção primária à saúde.

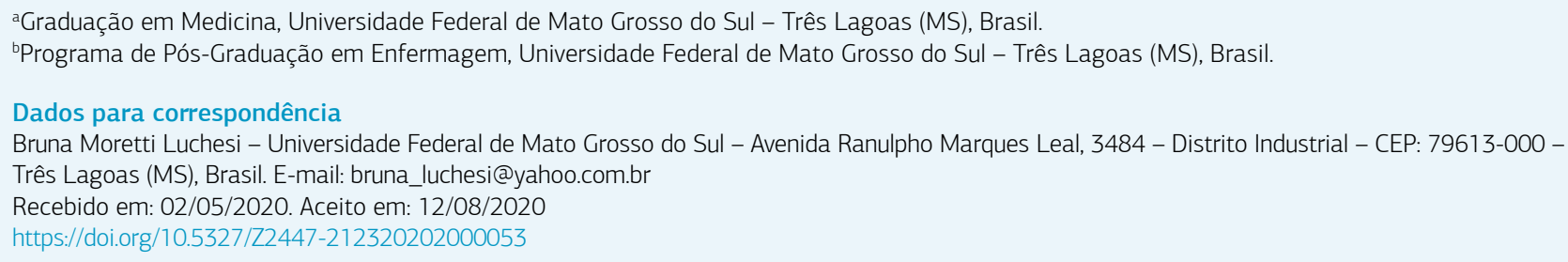




\section{INTRODUCTION}

Sleep is a naturally recurring mental and physical state, characterized by altered consciousness, relatively inhibited sensory activity, and reduced interaction with the environment. ${ }^{1}$ Sleep patterns change with aging, since many sleep disorders increase with age and are generally ignored, going undetected unless they are subject to comprehensive investigation. ${ }^{1}$

There is a significant prevalence of complaints related to sleep in clinical practice. ${ }^{2}$ It is known that sleep disorders are often associated with comorbidities, such as obstructive sleep apnea syndrome; diabetes mellitus; increased insulin resistance; arterial hypertension; dyslipidemia; and obesity, ${ }^{2}$ and also to several adverse outcomes, such as falls; cognitive deficits; and poor quality of life. ${ }^{3}$ Moreover, sleep quality has direct impacts on mood; immune response; social behaviors; hormone production; the physiological processes of the gastrointestinal tract; and psychological factors. ${ }^{4}$

Duration of nocturnal sleep can be related to age; sex; educational level; and income. ${ }^{5}$ The relationship between advancing age and sleep quality has also been associated with clinical; social; demographic; psychological; and lifestyle-related factors. ${ }^{6}$ In middle-aged adults and older adults, poor quality sleep has been linked to being a migrant worker; having a low educational level; having had a disease during the preceding weeks; and having a higher number of chronic diseases. ${ }^{7}$

Studies have demonstrated that there is a relationship between poor sleep and cognitive impairment. ${ }^{4,8}$ It is believed that this finding is due to information processing and consolidation of memory during sleep, which ensures neuronal plasticity and maintenance of central nervous system functions. ${ }^{4}$ The pathology underlying cognitive disorders can exist in the brain for periods ranging from years to decades before clinical symptoms manifest, and it is not yet known whether sleep disorders constitute an early marker of this pathology or a risk factor at onset or during progression of the disease. ${ }^{8}$

Various factors have been related to sleep disorders in the Brazilian literature. Among older people, they are more frequent in women, with diseases of the joints; nocturia; and urinary incontinence. ${ }^{9}$ In adults, factors such as female sex; low educational level; overweight; and obesity have been associated with sleeping problems. ${ }^{10}$

Therefore, this study's research effort is justified by the goal of elucidating the relationship between sleep and aging to attempt to fill certain gaps in the scientific perspective on the subject. In addition to variables commonly listed as associated with sleep disorders, this study also included variables related to social support networks, which is a relationship that has been explored little in Brazil. Increased study of sleep in aging is of fundamental importance because of the intrinsic physiological need for sleep to ensure quality of life during aging. The objective of the present study was therefore to identify sociodemographic; health; and social support network factors related to difficulty sleeping in adults and older people registered with Family Health Strategy (FHS) units.

\section{METHODS}

This is a cross-sectional study employing quantitative methods that was conducted in the town of Três Lagoas, in the Mid-West region of Mato Grosso do Sul state, Brazil. In 2010, the town had a population of 101,791 inhabitants, 16,394 (16.10\%) of whom were aged from 45 to 59 years and 10,067 (9.88\%) of whom were 60 or over. The town's estimated population in 2018 was 119,465 inhabitants. The study recruited adults over the age of 45 years who were registered at the nine Primary Care Health Centers that run the FHS $(41.10 \%$ coverage of the municipal district).

Sample size was calculated using the formula for estimation of proportions in descriptive studies with a qualitative categorical variable and finite population, adopting an alpha significance level of 5\% (alpha $=0.05)$ and assuming $5 \%$ sampling error $(\mathrm{e}=0.05)$. The $50 \%$ estimate $(\mathrm{p}=0.50)$ yielding the largest sample size was used. Considering a finite population of $n=200$, the minimum samples sizes were $n=132$ adults and $n=132$ older people.

The following inclusion criteria were defined for the study: age greater than or equal to 45 years; registered with the municipal district's FHS; and ability to answer the interview questions. Inability to answer was judged by the interviewer. People were excluded if they had untreated mental diseases or disorders or systemic diseases that prevented participation, such as neurocognitive disorders; schizophrenia spectrum disorders; or other psychotic disorders. Individuals meeting these exclusion criteria were identified by the interviewers asking study candidates about presence of these diseases and disorders and, if the participant replied in the affirmative, the information was confirmed with the healthcare team.

The health professionals on the FHS teams provided a list containing the names of people who met the inclusion criteria. The data collection team then selected people from the list at random until a final sample had been 
selected comprising 147 adults and 153 older people, totaling 300 participants.

Data were collected from November 2018 to June 2019. Face-to-face interviews were conducted by trained interviewers, who were supervised throughout the data collection process. The project was approved by the research ethics committee at the Universidade Federal de Mato Grosso do Sul (CAAE $\left.n^{\circ} 85481518.4 .0000,0021\right)$ and complied with all ethical principles. Participants read and signed free and informed consent forms before the interviews.

The data collection instrument covered sociodemographic data; health characteristics; and social support networks. The dependent variable difficulty sleeping was assessed using the self-report question: "Do you have difficulty sleeping?".

The independent variables investigated were grouped under the headings sociodemographic variables; health characteristics; and social support network:

- Sociodemographic variables: sex (male/female); age (mature adults: 45-59 years; older people: $\geq$ 60 years); educational level (years of study); marital status (has partner/no partner); and individual income $(\leq \mathrm{R} \$ 998>\mathrm{R} \$ 998$ - the value of the minimum monthly wage at the time of data collection);

- Health characteristics: hospital admission in preceding 6 months (yes/no); fall during preceding year (yes/no); smoking (yes/no); alcohol consumption (yes/no); number of medications/day (continuous variable); self-report of visual impairment (yes/no); self-report of hearing loss (yes/no); subjective health assessment (very good/good; regular; very bad/bad); and Mini-Mental State Examination (normal/abnor$\mathrm{mal}$ ). This last is a screening instrument for cognitive status that covers the domains orientation to time; orientation to place; registration; attention and calculation; recall; and language. The maximum score is 30 points. Previously validated cutoffs were used to classify participants by presence or absence of cognitive deficit (illiteracy: 20 points; $1-4$ years of education: 25 points; $5-8$ years: 26.5 points; $9-11$ years: 28 points; $\geq 11$ years: 29 points); ${ }^{11}$

- Social support network: participants were asked about the number of people living in their household (continuous variable); the number of people close to them - using the question: "Approximately, how many close friends or close family members do you have (people with whom you feel you can talk about anything)?" - (continuous variable); participation in leisure activities — using the question: "Do you take part in leisure activities?" - (yes/no); and self-report social isolation - using the question: "Do you consider yourself socially isolated” - (yes/no).

\section{Statistical analysis}

Data were input to a Microsoft Office Excel ${ }^{\mathrm{TM}}$ spreadsheet, with double-input, validation, and confirmation of data. They were then imported to SPSS version 25.0. Descriptive statistics were produced, calculating relative frequencies, means, and standard deviations. Subsets with and without difficulty sleeping were compared using the $\chi^{2}$ test for categorical variables and the Mann-Whitney $U$ test for continuous variables. Binomial logistic regression analysis was used to investigate associations between independent variables and the dependent variable - difficulty sleeping. Initially, univariate regression was performed to select variables for the model, adopting a criterion of $\mathrm{p}$ $\leq 0.20$. Forward stepwise selection was used to construct the multiple regression model using the variables selected. The final significance level adopted was 5\%for all tests. The regression analysis outputs Odds Ratios (OR) with their respective $95 \%$ confidence intervals $(95 \% \mathrm{CI})$ were used.

\section{RESULTS}

The prevalence of difficulty sleeping was $43 \%$ (95\%CI 37 - 49). Table 1 lists the principal characteristics of the study participants, broken down by the variable of interest (with or without difficulty sleeping). The variables sex; fall during the last year; self-report of visual deficits; self-report of hearing loss; self-assessed health status as bad/very bad; and social isolation were all associated with the outcome. Additionally, taking a higher number of medications per day and having fewer close friends and relatives exhibited associations with difficulty sleeping.

Table 2, lists the results of the adjusted logistic regression. According to the adjusted analyses, the following variables were associated with the outcome: female sex ( $\mathrm{OR}=2.08$; 95\%CI $1.21-3.60)$; number of medications/ day $(\mathrm{OR}=1.18$; 95\%CI $1.05-1.33)$; , self-report of visual impairment $(\mathrm{OR}=3.56$; 95\%CI $1.54-8.22)$; self-report of hearing loss $(\mathrm{OR}=2.28$; 95\%CI $1.18-4.41)$; and social isolation $(\mathrm{OR}=2.01 ; 95 \% \mathrm{CI} 1.14-3.54)$.

\section{DISCUSSION}

Difficulty sleeping was identified in $43 \%$ of the sample in the present study. 
Table 1. Sociodemographic characteristics, health data, and social support networks of participants with $(n=129)$ and without $(n=171)$ difficulty sleeping.

\begin{tabular}{|l|c|c|c|c|} 
Variables \% or Mean (SD) & $\begin{array}{c}\text { Total } \\
(\mathrm{n}=300)\end{array}$ & $\begin{array}{c}\text { With difficulty } \\
\text { sleeping } \\
(\mathrm{n}=129)\end{array}$ & $\begin{array}{c}\text { Without difficulty } \\
\text { sleeping }\end{array}$ & $(\mathrm{n}=171)$
\end{tabular}

\section{Sociodemographic characteristics}

\begin{tabular}{|c|c|c|c|c|}
\hline \multirow{2}{*}{ Sex* } & Male & 34.33 & 23.26 & 42.69 \\
\hline & Female & 65.67 & 76.74 & 57.31 \\
\hline \multirow{2}{*}{ Age (years) } & $45-59$ & 49.00 & 48.06 & 49.70 \\
\hline & $\geq 60$ & 51.00 & 51.94 & 50.30 \\
\hline \multicolumn{2}{|l|}{ Educational level (years) } & $5.75(4.61)$ & $5.55(4.24)$ & $5.89(4.87)$ \\
\hline \multirow{2}{*}{ Marital status } & Has partner & 56.00 & 53.48 & 57.89 \\
\hline & No partner & 44.00 & 46.52 & 42.11 \\
\hline \multirow{3}{*}{ Individual income (R\$) } & Over 998 & 36.67 & 32.56 & 39.77 \\
\hline & Up to 998 & 51.33 & 56.59 & 47.37 \\
\hline & Information not provided & 12.00 & 10.85 & 12.86 \\
\hline
\end{tabular}

Health characteristics

\begin{tabular}{|c|c|c|c|c|}
\hline \multirow{2}{*}{ Admission in last 6 months } & No & 89.67 & 86.82 & 91.81 \\
\hline & Yes & 10.33 & 13.18 & 8.19 \\
\hline \multirow{2}{*}{ Fall during the last year* } & No & 71.0 & 62.79 & 77.19 \\
\hline & Yes & 29.0 & 37.21 & 22.81 \\
\hline \multirow{2}{*}{ Smoking } & No & 81.33 & 76.74 & 84.79 \\
\hline & Yes & 18.67 & 23.26 & 15.21 \\
\hline \multirow{2}{*}{ Alcohol consumption } & No & 76.67 & 79.84 & 74.27 \\
\hline & Yes & 23.33 & 20.16 & 25.73 \\
\hline \multicolumn{2}{|l|}{ Number of medications/day* } & $2.24(2.30)$ & $2.78(2.53)$ & $0.73(0.45)$ \\
\hline \multirow{2}{*}{$\begin{array}{l}\text { Self-report of visual } \\
\text { impairment* }\end{array}$} & No & 15.33 & 6.98 & 21.63 \\
\hline & Yes & 84.67 & 93.02 & 78.37 \\
\hline \multirow{2}{*}{ Self-report of hearing loss* } & No & 82.67 & 75.97 & 87.72 \\
\hline & Yes & 17.33 & 24.03 & 12.28 \\
\hline \multirow{3}{*}{ Subjective health assessment* } & Very good/Good & 51.67 & 42.63 & 58.48 \\
\hline & Regular & 38.00 & 43.41 & 33.91 \\
\hline & Very bad/Bad & 10.33 & 13.96 & 7.61 \\
\hline \multicolumn{2}{|l|}{ MMSE } & $23.03(4.14)$ & $22.74(4.20)$ & 23.25 (4.09) \\
\hline \multicolumn{5}{|l|}{ Social support network } \\
\hline \multicolumn{2}{|l|}{ № people at home } & $3.02(1.64)$ & $2.96(1.56)$ & 3.06 (1.69) \\
\hline \multicolumn{2}{|l|}{ № close people* } & $6.83(8.08)$ & $5.86(7.07)$ & $7.57(8.72)$ \\
\hline \multirow{2}{*}{ Participation in leisure activities } & No & 50.50 & 56.25 & 46.19 \\
\hline & Yes & 49.50 & 43.75 & 53.81 \\
\hline \multirow{2}{*}{ Social isolation* } & No & 73.00 & 61.24 & 81.87 \\
\hline & Yes & 27.00 & 38.76 & 18.13 \\
\hline
\end{tabular}

SD: standard deviation; MMSE: mini mental state examination; ${ }^{\S} \chi^{2}$ test for categorical variables and Mann-Whitney $U$ test for continuous variables; ${ }^{*} p \leq 0.05$ 
Compared with other Brazilian data, this percentage was similar to the findings of a study conducted in a town in upstate São Paulo, in which $46.7 \%$ of a sample of 743 adults reported sleep disorders. ${ }^{10}$ In a study investigating primary care consultations in Rio Branco (AC), the prevalence was $33.3 \%{ }^{12}$ Internationally, the prevalence of sleep disorders was close to $33 \%$ in studies undertaken in Australia and in India. ${ }^{13,14}$ The differences in prevalence observed may be because of the characteristics of the sample in the present study, comprising mature adults and older people, in which being a woman; having visual impairment; having hearing loss; taking more medications; and self-assessing as socially isolated were the most prevalent variables among individuals with difficulty sleeping.
The principal factors considered influential over sleeping difficulties in adults and older people are listed and discussed below.

In the present study, women had a 2.08 times greater likelihood of difficulty sleeping than men. This result is compatible with those of a study with 775 individuals of both sexes conducted in a municipal district in the MidWest of Brazil, which found that female sex was associated with the outcome poor quality sleep..$^{15}$ These findings could be because of a range of different genetic and physiological factors. They suggested that, among the causes of sleep-related problems in women, factors such as stress; family conflicts; and the higher incidence of depression in this group were aspects which had negative impacts on

Table 2. Prevalence of difficulty sleeping and associated factors.

\begin{tabular}{|c|c|c|c|c|c|c|}
\hline \multirow{2}{*}{ Variables } & \multirow{2}{*}{ Categories } & \multirow{2}{*}{$\begin{array}{l}\text { Difficulty } \\
\text { sleeping \% or } \\
\text { Mean (SD) }\end{array}$} & \multicolumn{2}{|c|}{ Simple } & \multicolumn{2}{|c|}{ Adjusted } \\
\hline & & & OR & $95 \% \mathrm{Cl}$ & OR & $95 \% \mathrm{Cl}$ \\
\hline \multicolumn{7}{|c|}{ Sociodemographic characteristics } \\
\hline \multirow{2}{*}{ Sex } & Male & 29.13 & 1.00 & & & \\
\hline & Female & 50.25 & 2.46 & $1.47-4.08$ & 2.08 & $1.21-3.60$ \\
\hline \multicolumn{7}{|l|}{ Health characteristics } \\
\hline \multirow{2}{*}{$\begin{array}{l}\text { Fall during } \\
\text { the last year }\end{array}$} & No & 38.03 & 1.00 & & & \\
\hline & Yes & 55.17 & 2.00 & $1.21-3.32$ & - & - \\
\hline \multirow{2}{*}{ Smoking } & No & 40.57 & 1.00 & & & \\
\hline & Yes & 53.57 & 1.69 & $0.94-3.03$ & - & - \\
\hline \multicolumn{2}{|c|}{ Number of medications/ day } & $2.24(2.30)$ & 1.21 & $1.08-1.35$ & 1.18 & $1.05-1.33$ \\
\hline \multirow{2}{*}{$\begin{array}{l}\text { Self-report of } \\
\text { visual impairment }\end{array}$} & No & 19.56 & 1.00 & & & \\
\hline & Yes & 47.24 & 3.68 & $1.71-7.94$ & 3.56 & $1.54-8.22$ \\
\hline \multirow{2}{*}{$\begin{array}{l}\text { Self-report of } \\
\text { hearing loss }\end{array}$} & No & 39.52 & 1.00 & & & \\
\hline & Yes & 59.62 & 2.26 & $1.23-4.16$ & 2.28 & $1.18-4.41$ \\
\hline \multirow{3}{*}{$\begin{array}{l}\text { Subjective health } \\
\text { assessment }\end{array}$} & Very good/ Good & 35.48 & 1.00 & & & \\
\hline & Regular & 49.12 & 1.75 & $1.07-2.87$ & - & - \\
\hline & Very bad/ Bad & 58.06 & 2.52 & $1.15-5.52$ & - & - \\
\hline \multirow{2}{*}{ MMSE } & Normal & 39.25 & 1.00 & & & \\
\hline & Abnormal & 49.12 & 1.49 & $0.93-2.39$ & - & - \\
\hline \multicolumn{7}{|c|}{ Social support network } \\
\hline \multicolumn{2}{|l|}{ No close people } & $6.83(8.08)$ & 0.97 & $0.94-1.01$ & - & - \\
\hline \multirow{2}{*}{$\begin{array}{l}\text { Participation in } \\
\text { leisure activities }\end{array}$} & No & 47.68 & 1.00 & & & \\
\hline & Yes & 37.83 & 0.67 & $0.42-1.06$ & - & - \\
\hline \multirow{2}{*}{ Social isolation } & No & 36.07 & 1.00 & & & \\
\hline & Yes & 61.73 & 2.86 & $1.69-4.84$ & 2.01 & $1.14-3.54$ \\
\hline
\end{tabular}

SD: standard deviation; OR: Odds Ratio; *p according to simple and adjusted analyses. 
sleep, whether in isolation or in combination. ${ }^{9}$ Moreover, over the course of their lifetimes, women undergo physiological hormonal changes, with reductions in the levels of ovarian estrogen and estradiol, which can compromise their ability to maintain their daily activities and provoke consequences for sleep quality. ${ }^{16,17}$ Since the sample was made up of people over the age of 45 years, the loss of sleep quality among women may be related to the menopause.

Advancing age was not related to difficulty sleeping. While such a relationship has been detected previously ${ }^{18}$ and some studies report that sleep disorders are common in older people, ${ }^{1,9}$ in an investigation conducted with 743 adults and older people from Presidente Prudente (SP), age was also unrelated to sleep disorders in an adjusted model. ${ }^{10}$

Rational use of medications is a relevant factor in view of the pharmacokinetic and pharmacodynamic characteristics of the older population. Reduced liver and kidney function and a lower proportion of water are the most important differences in the physiology of older people that have direct implications. Indeed, circadian and metabolic changes are to be expected when medications are being used. Furthermore, polypharmacy is intimately associated with people's senescence processes. As such, rational use of drugs is a fundamental pillar of maintenance of quality of life as aging progresses. ${ }^{19}$ In the present study, the number of medications that participants took each day was significant, confirming the need for drug management, considering the multiple comorbidities present.

In this study, visual impairment was associated with difficulty sleeping. The lack of studies investigating problems pertaining to sleep in people with visual disorders means that it is difficult to relate our findings to data in the literature. A review of the literature found that, although studies of this association are increasing, the pathophysiology underlying the mechanisms is still poorly understood. ${ }^{20}$ Nevertheless, recognition of the existence of an association is important to encourage health professionals to recommend ophthalmological examinations to patients with problems sleeping, and also to assess the sleep quality of patients with visual impairment. ${ }^{20}$ Another investigation, of 6784 glaucoma patients from the United States, found a relationship between the disease and abnormal sleep duration, sleep latency, and diurnal dysfunction, in which poor sleep parameters could equally be a consequence of disease or a risk factor. ${ }^{21}$

Additionally, the result observed may be related to the fact that people with visual impairment are more likely to have anxiety, which, consequently, results in a higher prevalence of sleep disorders. ${ }^{22}$

The present study also detected a higher prevalence of self-reported hearing loss among people with difficulty sleeping, with a significant association between these two variables, in line with the results of a systematic review ${ }^{23}$ and of a study using an animal model. ${ }^{24} \mathrm{~A}$ study conducted in Brazil confirmed this association, reporting better quality sleep in 50 older people with hearing loss after they began to wear hearing aids. ${ }^{25}$ Another strand of the literature holds that hearing loss is the initial factor, increasing anxiety (a negative psychological state that is already known to have a negative impact on sleep) and altering neural plasticity with negative changes to sleep patterns. ${ }^{26}$ This duality is indicative of a need for more studies investigating this relationship.

The results of this study showed a positive association between social isolation and difficulty sleeping. Both factors are common in older people, but merit study targeting attenuation of their physical and mental consequences. The same correlation was also observed in studies undertaken in the United States. ${ }^{27,28}$ Social isolation has been identified as a more relevant factor in sleep disturbances than the feeling of loneliness. ${ }^{29} \mathrm{~A}$ lack of sleep leads to a neural and behavioral phenotype of social withdrawal with a self-reinforcing feedback cycle of separation and withdrawal from society. ${ }^{29}$ In turn, the increase in feelings of isolation during the daytime precedes worse sleep quality at night, culminating in increased isolation the following day - setting up another vicious circle. ${ }^{30}$ The roles of cause and consequence of difficulty sleeping and social isolation have not yet been established in the literature, showing that there is a research gap to be explored.

The results of this study should be interpreted in the light of certain limitations. The cross-sectional design does not allow inferences of the causal effects between the variables investigated and longitudinal studies would be needed to establish such effects. Since the sample only included people registered with the FHS, the result may have been selection of a homogenous group of people who have access to healthcare, making it only possible to generalize the data within this context. The sample may not correspond to the situation of the mature and older adult population in the municipal district and, although a sample size calculation was used, the data should be treated with caution and cannot be generalized to the population. Furthermore, some variables, such as number of medications, visual impairment, and hearing loss, were self-reported, which is another limitation. 


\section{CONCLUSIONS}

The unfavorable implications of the process of aging of the population reveal challenges that health professionals and all who seek to maintain quality of life in aging must overcome. In this context, sleep, as a restorative biological tool, becomes a dilemma when it ceases to be a habit and becomes a symptom of physical depletion in adults and older people, - which is a subject that has not yet been fully explored from the therapeutic and behavioral point of view. This study has proven indispensable to construction of knowledge of the prevalence of difficulty sleeping and factors related to aging: female sex; higher number of medications used per day; visual impairment; hearing loss; and social isolation.

It is thus important to emphasize the need to individualize care for people who have problems sleeping. Identification of the principal predisposing factors is of relevance to supporting planning of care and of public policies, targeting improved sleep quality among mature adults and older people. Sleep disorders can become debilitating and it is essential that they be correctly managed by healthcare services in all sectors, whether public or private. The study data are particularly important for primary healthcare interventions. Sleep should be made a target for transformation of the individual concept of wellbeing, rather than a component of comorbidities.

\section{CONFLICTS OF INTEREST}

The authors declare that there are no conflicts of interest.

\section{FUNDING}

This study was conducted with support from the Universidade Federal de Mato Grosso do Sul and the Coordenação de Aperfeiçoamento de Pessoal de Nível Superior - Finance Code 001.

\section{AUTHORS' CONTRIBUTIONS}

BML: concept, data curation, formal analysis, administration of the project, supervision and writing - revision and editing. TCRM: concept, data curation, formal analysis, administration of the project, supervision and writing - revision and editing. AMFR: investigation, visualization, and writing - first draft. FCO: investigation, visualization, and writing - first draft. LAS: investigation, visualization, and writing - first draft.

\section{REFERENCES}

1. Tufan A, Ilhan B, Bahat G, Karan MA. An under-diagnosed geriatric syndrome: Sleep disorders among older adults. Afr Health Sci. 2017;17(2):436-44. http://doi.org/10.4314/ahs. v17i2.18

2. Neves GSML, Giorelli AS, Florido P, Gomes MDM. Transtornos do sono: visão geral. Rev Bras Neurol. 2013;49(2):57-71.

3. Peron TC, Togeiro SM, Nakaema KE, Araujo LMQ, Tufik S, Cendoroglo MS. Fatores associados à polissonografia em idosos independentes. Geriatr Gerontol Aging. 2016;10(4):182-8. http://doi.org/10.5327/ Z2447-211520162016007

4. Acosta MT. Sueño, memoria y aprendizaje. Medicina (B Aires). 2019;79(Supl. 3):29-32.

5. Chaput JP, Wong SL, Michaud I. Duration and quality of sleep among Canadians aged 18 to 79. Health Rep. 2017;28(9):28-33.

6. Lo CMH, Lee PH. Prevalence and impacts of poor sleep on quality of life and associated factors of good sleepers in a sample of older Chinese adults. Health Qual Life Outcomes. 2012;10:72. http://doi. org/10.1186/1477-7525-10-72

7. Zhang HS, Li Y, Mo HY, Qiu DX, Zhao J, Luo JA, et al. A communitybased cross-sectional study of sleep quality in middle-aged and older adults. Qual Life Res. 2017:26(4):923-33. http://doi.org/10.1007/ s11136-016-1408-1

8. Yaffe K, Falvey CM, Hoang T. Connections between sleep and cognition in older adults. Lancet Neurol. 2014;13(10):1017-28. http://doi. org/10.1016/S1474-4422(14)70172-3

9. Moreno CRDC, Santos JLF, Lebrão ML, Ulhôa MA, Duarte YADO. Sleep disturbances in older adults are associated to female sex, pain and urinary incontinence. Rev Bras Epidemiol. 2019;21(Supl. 2):e180018. https://doi.org/10.1590/1980-549720180018.supl.2
10. Zanuto ACE, Lima CSM, Araújo GR, Silva PE, Anzolin CC, Araujo YCM, et al. Distúrbios do sono em adultos de uma cidade do estado de São Paulo. Rev Bras Epidemiol. 2015;18(1):42-53. https://doi. org/10.1590/1980-5497201500010004

11. Brucki SMD, Nitrini R, Caramelli P, Bertolucci PHF, Okamoto IH Sugestões para o uso do mini-exame do estado mental no Brasil. Arq Neuro-Psiquiatr. 2003;61(3B):777-81. https://doi.org/10.1590/ 50004-282X2003000500014

12. Feitosa DJC, Oliveira SMC. Prevalência de sintomas relacionados ao sono na atenção primária à saúde. Rev Neurocienc. 2015;23(2):16572. http://doi.org/10.4181/RNC.2015.23.02.1012.8p

13. Cunnington D, Junge MF, Fernando AT. Insomnia: prevalence, consequences and effective treatment. Med J Aust. 2013;199(S8):S36-S40. http:// doi.org/10.5694/mja13.10718

14. Bhaskar S, Hemavathy D, Prasad S. Prevalence of chronic insomnia in adult patients and its correlation with medical comorbidities. J Family Med Prim Care. 2016;5(4):780-4. http://doi.org/10.4103/2249-4863.201153

15. Simões ND, Monteiro LHB, Lucchese R, Amorim TA de, Denardi TC Vera I, et al. Qualidade e duração de sono entre usuários da rede pública de saúde. Acta Paul Enferm. 2019;32(5):530-7. https://doi. org/10.1590/1982-0194201900074

16. Lima AM, Rocha JSB, Reis VMCP, Silveira MF, Caldeira AP, Freitas RF, et al. Loss of quality of sleep and associated factors among menopausal women. Cienc Saude Coletiva. 2019;24(7):2667-78. http://dx.doi.org/10.1590/1413-81232018247.19522017

17. Corrêa KM, Bittencourt LRA, Tufik S, Hachul H. Frequência dos distúrbios de sono em mulheres na pós-menopausa com sobrepeso/obesidade. Rev Bras Ginecol Obstet. 2014;36(2):90-6. https://doi.org/10.1590/ S0100-72032014000200008 
18. Campos Costa I, Carvalho HN, Fernandes L. Review Article Aging, circadian rhythms and depressive disorders: a review. Am J Neurodegener Dis. 2013;2(4):228-46.

19. Meneses ALL, Sá MLB. Pharmaceutical care of the elderly: basis and proposals. Geriatr Gerontol Aging. 2010;4(3):154-61.

20. Waller EA, Bendel RE, Kaplan J. Sleep disorders and the eye. Mayo Clin Proc. 2008;83(11):1251-61. http://doi.org/10.4065/83.11.1251

21. Qiu M, Ramulu PY, Boland MV. Association between Sleep Parameters and Glaucoma in the United States Population: National Health and Nutrition Examination Survey. J Glaucoma. 2019;28(2):97-104. http:// doi.org/10.1097/IJG.0000000000001169

22. Silva BBR da, Lacerda KRRS, Ferreira AP de L, Figueiroa M de S. Prevalência de bruxismo e distúrbio do sono em deficientes visuais. Fisioter Mov. 2013;26(1):159-66. https://doi.org/10.1590/S010351502013000100018

23. Clarke NA, Hoare DJ, Killan EC. Evidence for an Association Between Hearing Impairment and Disrupted Sleep: Scoping Review. Am J Audiol. 2019;28(4):1015-24. https://doi.org/10.1044/2019_aja-19-0026

24. Jung JH, Kim M, Lee SJ, Lee E, Lee SA, Lee JD, et al. Effect of sleep deprivation on hearing levels in rats. Int J Pediatr Otorhinolaryngol. 2018;112:169-75. http://doi.org/10.1016/j.jporl.2018.07.003
25. Gomes NHG, Terra NL. The influence of hearing aid in quality of life of the elderly. Geriatr Gerontol Aging. 2013;7(2):136-41.

26. Zarenoe R, Hällgren M, Andersson G, Ledin T. Working memory, sleep, and hearing problems in patients with tinnitus and hearing loss fitted with hearing aids. J Am Acad Audiol. 2017;28(2):141-51. http://doi. org/10.3766/jaaa.16023

27. Hawkley LC, Capitanio JP. Perceived social isolation, evolutionary fitness and health outcomes: a lifespan approach. Philos Trans R Soc Lond B Biol Sci. 2015;370(1669):20140114. http://doi.org/10.1098/ rstb.2014.0114

28. Simon EB, Walker MP. Sleep loss causes social withdrawal and loneliness. Nat Commun. 2018;9:3146. http://doi.org/10.1038/ s41467-018-05377-0

29. Yu B, Steptoe A, Niu K, Ku PW, Chen LJ. Prospective associations of social isolation and loneliness with poor sleep quality in older adults. Qual Life Res. 2018;27(3):683-91. http://doi.org/10.1007/s11136017-1752-9

30. Cho JHJ, Olmstead R, Choi H, Carrillo C, Seeman TE, Irwin MR. Associations of objective versus subjective social isolation with sleep disturbance, depression, and fatigue in community-dwelling older adults. Aging Ment Health. 2019;23(9):1130-8. https://dx.doi.org/10.1080/13607 863.2018 .1481928 